\title{
Simulated paraplegia: an occasional problem for the neurosurgeon
}

\author{
RS MAURICE-WILLIAMS, H MARSH \\ From the Royal Free Hospital and School of Medicine, London, UK
}

SUMMARY Fourteen cases of simulated paraplegia and tetraplegia encountered amongst 4,800 neurosurgical admissions are described. The classification of such cases is difficult. Use of the term "hysteria" depends on whether the behaviour is judged to be conscious or not, but this can rarely be decided. In most of the patients the paralysis was of relatively short duration and recovered rapidly with simple methods of treatment which permitted this to occur without loss of face, but such cases presenting as acute neurological emergencies represent only one relatively simple form of pretended or "hysterical" illness. Many of these patients are probably never seen by psychiatrists.

From time to time most clinicians encounter patients whose illnesses are believed to be factitious. Such a diagnosis can seldom be made with confidence, but if it is a neurological disorder which is being mimicked, it may be possible to demonstrate inconsistencies which point to a non-organic basis. The classification of such patients as hysterics or malingerers depends upon whether the pretence is judged to be unconscious or conscious. In practice this distinction can seldom be made.'

We describe 14 cases of pretended or hysterical paraplegia and tetraplegia encountered amongst 4,800 neurosurgical admissions. It is known that there are fashions in hysteria and it seems possible that paraplegia has become one of its commoner manifestations. This might reflect increased pubiic awareness of the fact that injury or disease of the vertebral column can be complicated by paralysis of the limbs.

\section{Patients studied}

Between February 1973 and September 1983, 34 patients diagnosed as suffering from hysterical or simulated illness, were encountered by the first author amongst 4,800 neurosurgical admissions $(0.7 \%)$ at St Bartholomew's Hospital, the Brook Hospital, and the Royal Free Hospital. These patients' manifestations are shown in table 1 . The criteria for the diagnosis are contained in the discus-

Address for reprint requests: Mr RS Maurice-Williams, Royal Free Hospital, Pond St, London NW3 2QC, UK

Received 2 July 1984 and in revised form 30 November 1984 Accepted 14 January 1985 sion section. This paper is concerned with the 14 of these patients who had a paraplegia or tetraplegia, which represented $1.5 \%$ of the admissions with spinal complaints over the same period.

\section{Patient characteristics}

There were 7 males and 7 females, whose ages at presentation ranged from 17 to 41 years. Eleven had paraplegias, 3 tetraplegias. Their occupational status was: upper professional-0; lower professional 2; skilled manual 5; unskilled 7 . The patients included 2 servicemen, an auxiliary nurse and a trainee social worker. Four patients had previous hospital admissions with organic illness. Previous psychiatric diagnoses included: anorexia nervosa (2), hyperventilation (1); impotence of psychogenic origin (1); personality disorder (2); hysterical illnesses (2); “nervous breakdown" (1). In two patients the paralysis was accompanied by a fantastic Munchausen type story which was easily proved to be false. The duration of paralysis at the time of neurosurgical admission was under 7 days in $6 ; 1$ week to 1 month in $3 ; 1$ month to 6 months in 4 ; over 6 months in 1 .

\section{Investigations}

Eight patients were subjected to myelography and examination of the cerebrospinal fluid, five had visual-evoked

Table 1 Simulated (or grossly exaggerated) illness

\begin{tabular}{lr}
\hline Paraplegia/tetraplegia & 14 \\
Monoplegia & 3 \\
Hemiplegia & 3 \\
Altered consciousness & 3 \\
Seizures & 2 \\
Blindness & 2 \\
Others & 7 \\
Total & 34 \\
\hline
\end{tabular}


Table 2 Precipitating physical illness

Minor spinal injury

Back pain/sciatica

Spinal surgery

Metastatic spinal diseases

Table 3 Psychological origin of paralysis

\begin{tabular}{lc}
\hline Unknown & 2 \\
Psychological Illness & $2:-$ \\
Paranoid schizophrenia & 1 \\
Anxiety state & 1 \\
Possible Motive Apparent & $10:-$ \\
Claim for compensation/benefit & 4 \\
Sick role & 3 \\
Revenge against spouse/employer & 2 \\
Escape from sexual difficulties & 2 \\
Discharge from army & 1 \\
Avoiding exam & 1 \\
Manipulation of boyfriend & 1
\end{tabular}

( ${ }^{*}$ In some cases, more than one possible motive was apparent, so the total exceeds 10)

\section{Table 4 Immediate outcome}

\begin{tabular}{lll}
\hline & \multicolumn{2}{l}{ Symptoms present } \\
\cline { 2 - 3 } & $\begin{array}{l}\text { Under } \\
\text { l month }\end{array}$ & $\begin{array}{l}\text { Over } \\
\text { I month }\end{array}$ \\
\hline Rapid full recovery & 9 & 2 \\
Delayed full recovery & - & 1 \\
Partial/fluctuating recovery & - & 2 \\
Total & 9 & 5 \\
\hline
\end{tabular}

responses, two had spinal CT scans and one had nerve conduction studies. All these investigations were normal. Five patients had no special investigations other than spine radiography.

\section{Origin of the paralysis}

In all cases the paralysis developed on the background of some physical illness of or injury to the spine insufficient to explain the paralysis. These originating illnesses are listed in table 2 . These spinal symptoms were in some cases present for weeks or months before paralysis appeared. The apparent psychological bases of the symptoms are listed in table 3 . In two cases the paralysis appeared symptomatic of an underlying psychological disorder and remitted when this was treated. In the remaining patients a motive (sometimes more than one) was apparent in ten.

\section{Treatment and outcome}

Hypnosis was employed in two patients, amytal abreaction in six patients. One patient was treated with phenothiazines, one with tranquillising agents and one received formal psychotherapy. For seven patients the only treatment consisted of firm reassurance and placebo injections.

The immediate outcome of treatment is shown in table 4. All nine cases where the paralysis was of short duration (under one month) recovered fully within 24 hours of admission. Two patients made incomplete recoveries from their paralyses. In both of these cases, the symptoms were of several months' duration.
Follow up

Thirteen patients were not followed up as out patients for fear of reinforcing their sickness behaviour. Follow up by letter to their family doctors revealed that seven patients had left their general practitioners' lists within 6 months of being discharged from hospital. One of these was known to have moved 30 miles away where he had readopted a paraplegic role. The other six remained well before they were lost to sight. Of the remaining patients, one died of disseminated carcinoma within one year without any relapse of paraplegia; one, who had not fully recovered, showed marked variability in his symptoms over the next 3 years, these variations being related to circumstances concerned with the payment of disability benefit. One patient was troubled by back pain 9 months after discharge but had had no relapse of paralysis. In four cases we were unable to obtain any follow up information.

\section{Illustrative case histories}

\section{Case 1 Shortlived paralysis, rapid full recovery, motive} evident

A 20-year-old WRAC private fell down stairs while at home on leave. She stated that she had hurt her back and could not move or feel her legs. Two days later, after a domiciliary visit, she was referred by a surgeon with suspected compression of her cauda equina from a central disc protrusion. She had not been incontinent. On admission there appeared to be no movement or feeling in her legs. Because of the lack of sphincter disturbance, the lack of reflex changes and a rather childish and unconcerned manner, a factitious illness was suspected. With firm reassurance, her paraplegia disappeared within 3 hours and she was able to walk round normally. Two days later it was learnt that she had had a variety of bizarre illnesses thought by her army medical officer to be hysterical. One of these had involved a self-inflicted wound. It was believed that she was keen to obtain a discharge from the army on medical grounds.

Case 2 Long standing paralysis. Complex motivation. Delayed abrupt recovery. Subsequent relapse

This 32-year-old labourer had gradually lost the use of his legs two years before, following two operations for lumbar disc disease. He was referred for a diagnosis as the cause of his paraplegia was uncertain. Although totally paraplegic and confined to a wheelchair, he had had no sphincter disturbance. He had become very active in charitable work for the disabled and had himself taken part in international games for paraplegics. On examination, no voluntary movements of the legs could be elicited and there was apparently complete sensory loss below the waist. His legs were held stiffly but there were none of the reflex changes, trophic changes, contractures or pressure sores that might have been expected in a chronic paraplegic. Repeated sessions of hypnosis and amytal abreaction did not lead to recovery of the paraplegia but two facts emerged. First, the patient had become a person of consequence as a result of his paraplegia and his involvement in charity work. Second, his first wife had left him for another man because of his supposed sexual inadequacy, just before the onset of paralysis. Subsequently he had remarried, but because of 
his paraplegia he was not obliged to try to consummate the marriage. The patient appeared unhappy as these facts came to light. After ten days he suddenly took his own discharge one evening. Leaving his crutches and wheelchair behind he walked off the ward and took the night train back to Cornwall. Later enquiry of his family doctor revealed that two weeks after discharge he had moved to another part of Cornwall and had resumed a wheelchair existence.

\section{Case 3 Paraplegia related to paranoid psychosis}

A 46-year-old woman underwent a negative exploration of several lumbar discs for low back pain and ill-defined leg pain. After operation she complained of unbearable pain in the back and gradually lost the use of her legs. Myelography was normal. There was no evident cause for the paraplegia and after a month she was referred for a neurosurgical opinion. There were no voluntary movements in the legs but no reflex changes could be found and there had been no incontinence. The patient's manner appeared odd, withdrawn and resentful. Three days after admission she developed a florid paranoid psychosis, accusing other patients of plotting against her and the nurses of stealing her possessions. She was treated with chlorpromazine, $1000 \mathrm{mg}$ a day and within a few days her mental state had returned to normal, her pain had gone and her paraplegia had completely recovered.

Case 4 Complex motivation. Recovery attributed by patient to "manipulation of the spine"

This 41-year-old dairyman and part-time male nurse had had "a nervous breakdown" at the age of 16 years. Four months before his admission he developed severe low back pain after lifting a heavy weight at work. The pain persisted, he failed to return to work and instituted a claim for compensation. A period of in-patient traction improved his symptoms but after a door slammed against his leg during a dispute with his wife, he complained of neck and back pain and said that he was numb from the waist down and could not move his legs. At the time of neurosurgical admission he had been paraplegic for four days. At first his manner appeared placid but on close questioning he became agitated and histrionic. He had not been incontinent and there had been no changes in his leg reflexes or tone. Sensation and movement began to recover shortly after his admission. The patient was told that he was suffering from "nervous shock" and that full recovery would occur. This took place within 24 hours. The patient declared himself cured and attributed this cure to manipulation of his spine. The manipulation had amounted to no more than the usual clinical examination of the spine.

\section{Case 5 Presence of Munchausen fantasy}

This 24-year-old window cleaner presented at a casualty department with a story that for two weeks he had been gradually losing the use of his limbs and had become impotent. He also said that he felt dizzy, had blurred vision and had been doubly incontinent for two days. He stated that he had sustained a head and neck injury four years previously while engaged on highly secret duties as an intelligence officer in Northern Ireland. He stated that two bricks had fallen on his head while he was standing in an armoured personnel carrier and that, although not rendered unconscious, he had been detained in a military hospital for three months with hairline fractures of his skull and two cervical vertebrae. He was a rather overweight, unfit looking young man. His speech, manner and build made his story of having been an intelligence officer in Ulster appear highly implausible, yet this story had been accepted by several doctors without question. He had a very severe but variable jerky weakness of all four limbs but no changes of tone or reflexes and no sensory loss. The apparent degree of weakness should have precluded weight-bearing, yet with reassurance he was induced to stand and walk a few steps. On close questioning his manner became evasive. He stated that as his work in the army had been highly secret; no records would have been kept of him. Eventually he was persuaded to give an army number. Enquiries revealed that his only connection with the army had been a period of three months as a junior soldier at the age of 16 , when he had been judged to be psychologically unfit for a service career. The patient was told that he had no sign of serious physical disease. His limb weakness rapidly evaporated, he became abusive and took his own discharge. One week later he returned to the ward, complaining of tension-type headaches. There had been no relapse of his tetraplegia.

\section{Discussion}

There are obvious dangers in diagnosing a factitious illness, but the failure to make such a diagnosis can be equally dangerous if, as a result, a patient is subjected to hazardous investigations or treatment, ${ }^{2}$ In the cases reported here, there was felt to be no reasonable doubt of the diagnosis.

For the diagnosis, fulfilment of three criteria was required. First, no physical explanation for the paralysis should be apparent. Second, it should be possible to demonstrate inconsistencies belying an organic basis. Third, it should be possible to produce a rapid improvement of symptoms with methods of treatment such as hypnosis, reassurance or amytal abreaction. The first two criteria are standard, but the last is a novel one. However we believe it is important for it to be met, if one is to avoid mistaking obscure physical disease for a functional disorder. A simulated illness was suspected, and may indeed have been present, in many additional cases bacause of the presence of the first two criteria, but the diagnosis was only regarded as confirmed if it was possible to produce rapid improvement of the paralysis by such means. The use of this criterion means of course that the diagnosis of factitious paralysis remains provisional until the response to treatment is known.

In one of our cases (case 2) treatment had no immediate effect, but after 10 days the patient abruptly "recovered" in a fashion that left the diag- 
nosis in no doubt. With two further patients treatment led to a sudden recovery of function which was very marked but not complete.

Amongst the inconsistencies commonly found on physical examination were total loss of pinprick and light touch in a limb with preservation of joint position sense and graphaesthesia and an inconsistent variability of weakness. For instance a complete paralysis of the legs when the patient was tested lying down might co-exist with the ability to stand up. If paralysis had been present for some while, the reflex changes expected with an organic pathology were not seen. Wasting, trophic changes, contractures and pressure sores were not encountered. Only one patient reported any disturbance of sphincter function. Weakness was characterised by a jerky simultaneous contraction of agonist and antogonist muscles. Sensory levels were often non-anatomical and could be shifted by suggestion.

Three patients were referred by general practitioners, 11 by consultants in other specialties (five orthopaedic surgeons, three rheumatologists, two general physicians, one radiotherapist). In only one case was a diagnosis of non-organic paralysis suspected prior to referral. This contrasts with a large number of cases seen over the same period of time, where a paralysis was diagnosed as functional at the referring hospital, but proved to have a physical cause. Such a misdiagnosis was frequently based on two circumstances, neither of which is sufficient for such a presumption. First, the clinician was unable to explain the paralysis. Second, the patient was judged to have a "hysterical personality". The concept of hysterical personality is not helpful in the diagnosis of hysterical illness. Patients who devleop hysterical illnesses show a wide range of personality characteristics. $^{3-5}$ Persons with "hysterical personalities" do not necessarily develop hysterical illnesses $^{6}$ and are as prone to develop physical illness as the rest of the population. Nevertheless, striking personality characteristics were noted in several of our patients. Five patients were judged to be immature and inadequate, three appeared unusually placid and unconcerned, and three seemed histrionic. The two sexes were equally represented.

A misdiagnosis of hysteria was especially common in one situation. This was when an elderly person became paralysed after a fall forwards onto the face. The absence of any radiological evidence of vertebral injury led to the diagnosis of hysteria, though it is known that sudden hyperextension of the neck can, in the presence of cervical spondylosis, cause a spinal cord contusion without any fracture or dislocation of the vertebral column. ${ }^{7}$

The subject of pretended or mimicked illness gives rise to nosological confusion. Much depends upon whether the pretence is believed to be conscious or unconscious. If the former, the patient may be assigned to some category such as malingering or the Munchausen syndrome; if the latter, the term "hysteria" or "hysterical conversion" may be used.' In practice it is seldom possible to decide the degree of consciousness involved with any degree of certainty, apart from the exceedingly rare occasions when a person confesses to deliberate deception. ${ }^{84}$

Perhaps one satisfactory solution to the problem of nomenclature is to put to one side the question of whether the patient is aware of the nature of his behaviour and just to categorise as "simulated illness" all phenomena such as hysterical conversion, Munchausen's syndrome, malingering, fugue states and dermatitis artefacta. Use of the word "hysteria" often gives rise to hopeless confusion although it is a word of such a long provenance that it is unlikely that it will ever be discarded. ${ }^{10}$ It is a word that is used in a number of different ways by psychiatrists and by laymen." "It contains connotations of histrionicity and femininity which are misleading, ${ }^{12}$ and in the past it has been used as if it referred to a disease state with some unified pathological basis. ${ }^{2}$ The very existence of hysteria has been doubted. ${ }^{13}$ Nevertheless, in many instances of simulated illness, it may be more helpful, from a practical point of view, to label the behaviour as "hysteria" rather than use a term such as "malingering" which implies fully conscious deception. If a descriptive label of the latter type is used, it is difficult to regard the person concerned as being a "patient' deserving of medical help,,$^{14}$ and he may unfairly be regarded as having complete insight into the way in which he is behaving. It has been argued that even in cases of the Munchausen syndrome, the patient may be under the control of psychodynamic forces of which he is not fully conscious. ${ }^{15}$ In other cases, behaviour which was originally conscious may have evolved into a learned "habit" which cannot be easily discarded by an act of will. ${ }^{\prime \prime}$

It is well established that certain conditions predispose to the occurrence of hysterical behaviour. Amongst these are depression, senile dementia, mental subnormality, epilepsy and multiple sclerosis..$^{46^{-18}}$ Many of these conditions have in common an impairment of the highest cerebral functions and it has been suggested that a propensity to pretend or to exaggerate illness indicates a childlike or immature way of behaving to which such patients have regressed. ${ }^{12}$ Most of the patients in this series came from the lower end of the social scale and had little evidence of any intellectual attainments.

Judging from our experience hysterical behaviour is seldom completely "pure". It has usually been erected on the basis of some relatively minor organic 
illness which may have had a triggering effect. ${ }^{2}$ In all our patients, an organic complaint initiated the behaviour. In seven patients there had been a trivial spinal injury, three patients had had an episode of low back pain or sciatica, three patients had had operations for lumbar disc protrusions and one patient had metastatic carcinoma of the spine without neurological involvement.

In two patients the origin of the paralysis appeared related to a definable psychological disorder. The patient with spinal metastasis was in a state of great anxiety about the possibility of paraplegia. The anxiety led to paralysis of the legs. Reassurance and the tranquillising agent led to the paraplegia recovering. In the other patient, the paraplegia accompanied an incipient paranoid psychosis which suddenly became florid. Treatment with a phenothiazine led to a rapid recovery of both the psychosis and the paraplegia. In ten of the remaining patients, a variety of motives for the development of paralysis became apparent. In two patients, no reason for the behaviour could be found.

Judging from our experience, the clue to successful treatment, at any rate in the short term, is somehow to convey to the patient that the nature of his behaviour is clearly understood. Success is more likely if this can be done with sympathy without any hint of disapprobation. At the same time the patient must be given some excuse for escaping from the situation he has created without humiliation, or loss of face. ${ }^{18}$ Such manoeuvres as hypnosis, amytal abreaction and injections of sterile saline may serve as reasons, in the patient's eyes, for a "cure" which would otherwise be difficult for him to explain. In some of the cases of short duration, firm and sympathetic reassurance was enough to lead to a rapid recovery. The usual approach was to tell the patient that his paralysis was due to "nervous shock" and that it would soon clear up.

In no case did removal of the paralysis lead to any immediate psychological crisis, violent behaviour or suicide. In most of our patients, a complete recovery of the paralysis was produced within hours of admission. It should not be inferred from this that most cases of simulated disease are so easily "cured". Our patients were a selected group by virtue of the fact that the illness they pretended was usually shortlived and of a clear-cut type which could easily be demonstrated to be factitious. Other cases of hysterical behaviour may be more complex involving the mimicking of ill-defined illnesses over a long period of time and perhaps with a complicated and deep-seated psychogenesis. Such cases might well be refractory to our simple modes of treatment, which of course did nothing to resolve the patient's underlying psychological problems.
The follow up information about our patients is limited. For fear of reinforcing "sickness behaviour" 13 patients were not given routine out patient follow up appointments. Inquiries were made of their family doctors about these patients. Seven of them had removed their names from their doctor's lists soon after discharge from hospital: six of these patients had been completely lost to sight. One was known to have moved to another area and to have resumed his paralysis. Of the remaining patients, only one was known to have had any later relapse of paralysis and no patients were known to have subsequently developed organic disease which might have been related to their paraplegia.

The high proportion of paraplegics and tetraplegics amongst our patients with simulated illness (14 out of 34 cases) is of interest. The paraplegic and tetraplegic cases represented approximately $1.5 \%$ of the neurosurgical admissions with spinal complaints. It may also be worth noting that all 14 patients lay within the age range 17 to 41 years. One may speculate on the reasons for this. It is known that there are fashions in hysteria. Tarantism and the dancing mania have long since disappeared, as have the sufferers from railay spine and the "grandes hysterie" of Charcot. ${ }^{219}$ The form that a hysterical or simulated illness takes will depend upon the patient's idea of the disease. ${ }^{4}$ With increasing sophistication of public knowledge about medical matters, at any rate amongst younger adults, it is probably becoming widely known that injury or disease of the vertebral column may lead to paralysis of the limbs. The frequency with which we have encountered the phenomenon described here may well reflect a better developed "idea of disease" than has been encountered in the past. Such relatively acute cases of simulated paralysis are likely to present as neurological emergencies. They will be seen in accident departments and by neurologists and neurosurgeons. If the paralysis is short-lived they may not be seen by psychiatrists, and it is possible that such cases occur much more frequently than psychiatric experience would suggest. ${ }^{2}$

We thank Mr R Campbell Connolly, Mr John Currie and Mr Bernard Fairburn, for permission to report on cases treated under their care at $\mathrm{St}$ Bartholomew's Hospital. We also thank the late Dr Shelagh Davies, Consultant Psychiatrist at the Royal Free and Maudsley Hospitals, for her helpful and constructive comments on this paper.

\section{References}

' Sim M. The management of Hysteria. In: Roy A, ed. 
Hysteria. Chichester: John Wiley, 1982:261-76.

${ }^{2}$ Merskey H. The Analysis of Hysteria. London: Bailliere Tindall, 1979.

${ }^{3}$ Chodoff $\mathrm{P}$, Lyons $\mathrm{H}$. Hysteria, the hysterical personality and "hysterical conversion". Am J Psychiatry 1958; 114:734-40.

${ }^{4}$ Roy A. Hysterical Neurosis. In: Roy A, ed. Hysteria. Chichester: John Wiley, 1982:89-98.

s Stephens J, Kamp M. On some aspects of hysteria: a clinical study. J Nerv Ment Dis 1962;134:305-15.

- Ziegler FJ, Imboden JB, Meyer E. Contemporary conversion reactions: a clinical study. Am J Psychiatry 1960;116:901-10.

${ }^{7}$ Maurice-Williams RS. Spinal Degenerative Disease. Bristol: Wright, 1981.

' Symonds C. Hysteria. Appendix C. In: Merskey H, ed. The Analaysis of Hysteria. London: Bailliere Tindall, 1979:258-65.

${ }^{9}$ Hurst AF. Medical Diseases of War. London: Edward Arnold, 1940.

${ }^{10}$ Lewis A. The Survival of hysteria. In: Roy A, ed. Hysteria. Chichester: John Wiley, 1982:21-26.
"Kendell RE. A new look at hysteria. In: Roy A, ed. Hysteria. Chichester: John Wiley, 1982:27-36.

${ }^{12}$ Lerner HE. The hysterical personality: a 'woman's disease'. Comp Psychiatry 1974;15:157-64.

${ }^{13}$ Slater E. What is hysteria? In: Roy A, ed. Hysteria. Chichester: John Wiley, 1982:37-40.

${ }^{14}$ Szasz TS. The Myth of Mental Illness. New York: Harper \& Row, 1961.

is Enoch MD, Trethowan WH. Uncommon Psychiatric Syndromes. Bristol: Wright, 1979.

${ }^{16}$ Langworthy OR, Legrand D. Personality structure and psychotherapy in multiple sclerosis. $\mathrm{Am} \mathrm{J} \mathrm{Med}$ 1952; 12:586-92.

${ }^{17}$ Merskey H, Buhrich NA. Hysteria and organic brain diease. Br J Med Psychol 1975;48:356-66.

${ }^{18}$ Pincus J. Hysteria presenting to the neurologist. In: Roy A, ed. Hysteria. Chichester: John Wiley, 1982:13143.

${ }^{14}$ Berry H. Psychological aspects of chronic neck pain following hyperextension-flexion strains of the neck. In: Morley TP, ed. Current Controversies in Neurosurgery. Philadelphia: Saunders, 1976:51-60. 